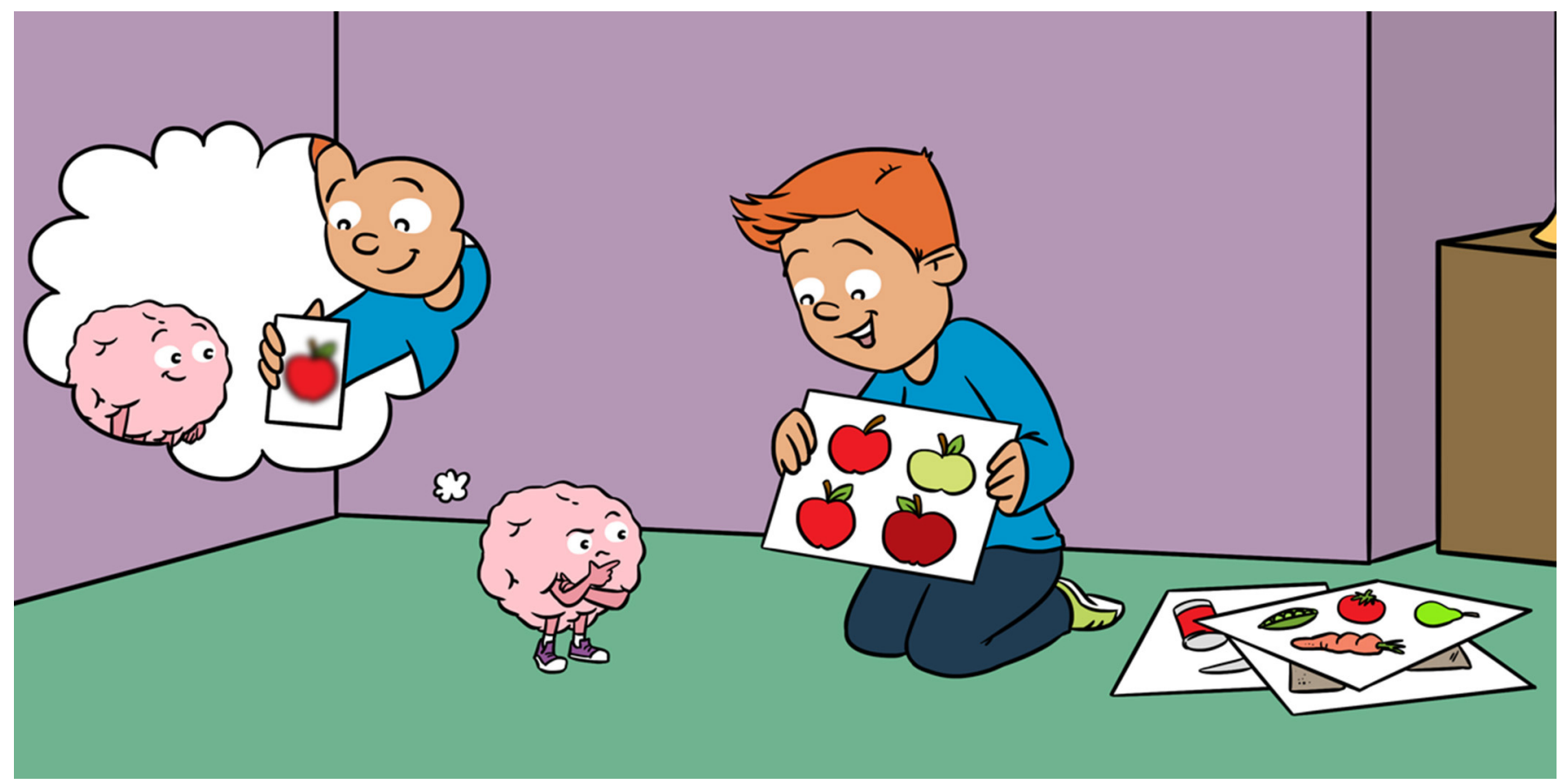

\title{
LEARNING BY ACCIDENT: SOME MEMORY MISTAKES ARE NOT TOTALLY WRONG
}

\author{
Juan D. Guevara Pinto ${ }^{1 *}$, Megan H. Papesh ${ }^{2}$ and Michael C. Hout ${ }^{2,3}$ \\ ${ }^{1}$ Department of Psychology, Rollins College, Winter Park, FL, United States \\ ${ }^{2}$ Department of Psychology, New Mexico State University, Las Cruces, NM, United States \\ ${ }^{3}$ National Science Foundation, Alexandria, VA, United States
}

YOUNG REVIEWERS:

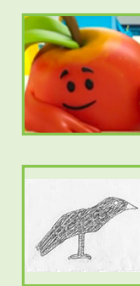

DALLIN

AGE: 12

WILDER

AGE: 12
When your parent picks you up from school, how do you know which car is theirs? You probably "just know," even without effortfully trying to memorize the brand, type, or color of the car. Although we often think of memory in terms of intentionally studying for tests, many memories are formed accidentally, without you even trying to intentionally learn something. But how detailed are these accidental memories? Do pieces of information remain, even if we feel like we have forgotten them? To explore these questions, we conducted an experiment in which participants searched through pictures, looking for specific objects. Later, and without warning, we asked people to choose previously seen pictures from a group of similar objects. Even when participants' choices were wrong, they often chose pictures that looked much like a picture they saw earlier. These "mistakes" do not reflect total forgetting, but instead show that people remember more than they think! 
INCIDENTAL

\section{MEMORY}

Information learned "by accident," without trying to remember what is in front of you.

\section{CAN WE REMEMBER THINGS "BY ACCIDENT"?}

Our visual world is gigantic; thousands of shape and color combinations make up all the distinct scenes and objects we see every day. During commercial breaks when watching TV, for instance, you probably do not care about the visuals in the ads: you see them, but you do not really pay close attention to them. Yet, your ability to remember specific pictures is much better than you might think. For example, research has shown that people can learn and recognize close to 10,000 different pictures, even if they only study each for a few seconds! [1]. And what is even more surprising is that many of these visual memories are incidental memories, that is, they are created almost by accident, without people even trying to remember what they saw.

We typically think of learning and memory as being intentional (on purpose), like sitting in a classroom trying to pay attention so you can remember everything later, during the test. Some memories, particularly for school-related information, are formed this way, and we retain the knowledge while gradually forgetting the details of when and where we first learned it. For example, you probably do not remember much about the place or day when you first learned the alphabet. However, many of our visual memories, such as those for places and the objects within them, are actually formed incidentally. Even though we do not try to remember these things, we can retain an impressive amount of detail. For instance, imagine that you are in the lunchroom looking for your friend Lily, who is saving you a seat. As you scan the room, you see people sitting at different tables and wearing many different color clothes, including Jeff, who is wearing a brown jacket. You eventually find Lily, have lunch, and head back to class. If, later that day, Jeff tells you that he lost his jacket, would you be able to help him pick it out of the cluttered lost-and-found box? In this example, you were not paying close attention to Jeff (you were looking for Lily), and probably only saw his jacket for a few seconds. Despite this, research shows that you would correctly spot Jeff's jacket in 8 tries out of 10 [2]. Some studies have even shown that you learn and remember visual information equally well whether you are trying to or not! [3].

\section{MEMORY "MISTAKES" ARE VERY INFORMATIVE}

Although many studies demonstrate that you can learn lots of visual information without trying [2-4], what would happen if several other jackets in the lost-and-found were also brown? Are incidental memories detailed enough that you would still find Jeff's jacket? Assessing the quality of memories is not easy. When researchers "measure" memory, we normally focus on a person's ability to choose the single correct answer in a memory test. If three of the jackets in the lost-and-found are brown, yellow, and blue, recognizing Jeff's brown 
Figure 1

A visual search task in which participants searched for one to four potential targets on each try, not knowing which, nor how many, of the target pictures would appear in the display. In the actual experiment, we used color images of real-world objects instead of clipart drawings.

\section{RANDOM GUESSING}

Equal likelihood of choosing any of the available options. In a coin toss, for example, your chance of randomly picking any one of the two outcomes is $50 \%$ (1 out of 2).

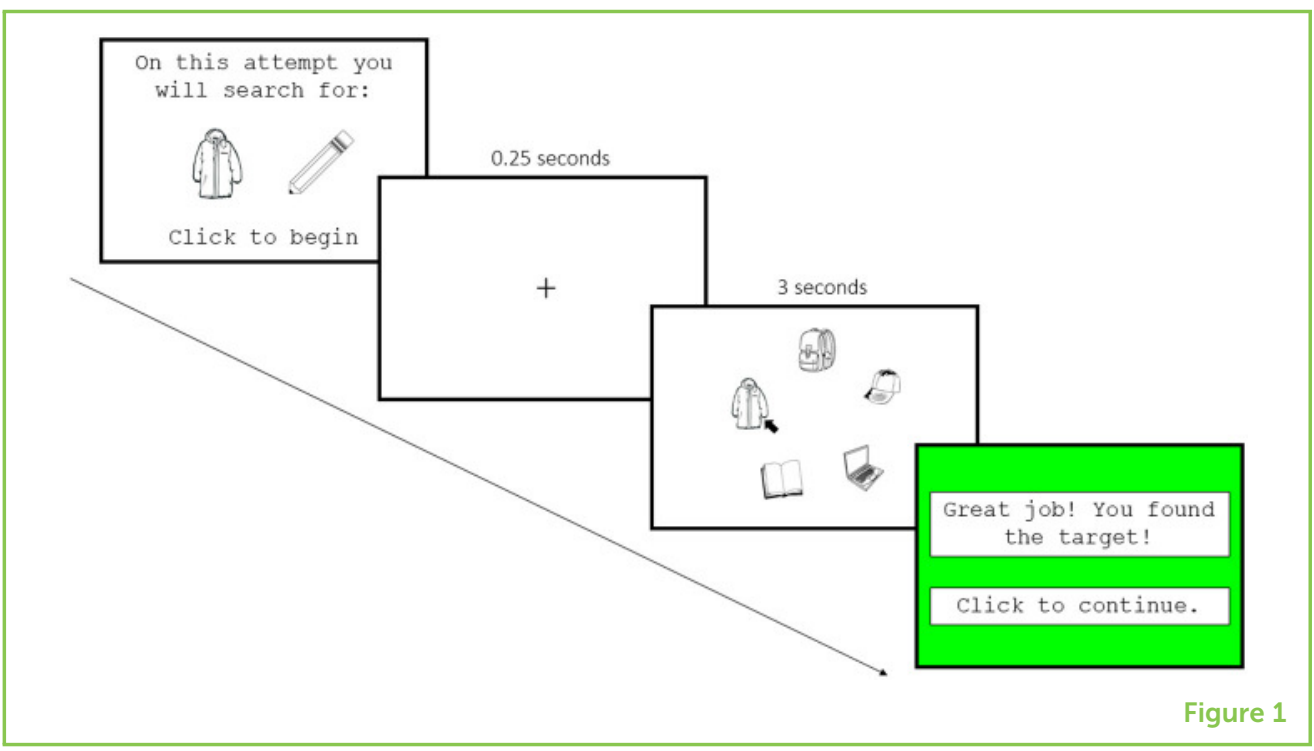

jacket is easy. If, however, there are many lost jackets and a few of them are brown, you might end up bringing Jeff the wrong brown jacket. Although this is a mistake, you still remembered enough to choose a similar jacket.

Now imagine that there are 16 jackets, and they are all brown! As the different options become more similar, recognizing the correct choice becomes more difficult, and memory mistakes become more common. Contrary to popular belief, these mistakes do not mean you have no memory for the object you are trying to remember. If you had no memory, you would be equally likely to bring Jeff a blue jacket as a brown one, as if you were randomly guessing. Instead, mistakenly choosing a similar brown jacket indicates that you do have a pretty detailed memory for Jeff's jacket, even if that memory is not "perfect."

\section{OUR INCIDENTAL MEMORY EXPERIMENT}

To measure how well-objects are remembered incidentally, we conducted an experiment in which people searched through pictures. This was similar to Where is Waldo? ${ }^{\circledR}$, except that people had to quickly find pictures of specific objects among pictures of other objects. For example, how quickly do you think you would have found one of the "target" pictures in Figure 1?

People had $3 \mathrm{~s}$ to use the computer mouse to click on the target picture as quickly as they could. This means that they had to quickly find the target picture and try to ignore the other "distractor" pictures. The participants looked for different target pictures among new sets of distractor pictures over and over again-200 times! After all 200 searches, we surprised them with a memory test for the distractor 
Figure 2

Experiment participants were given a surprise memory test after the experiment explained in Figure 1. In this example, participants saw one of these backpacks as a distractor during the visual search task. In the memory test, they had to choose which of the four similar-looking backpacks they saw. As in the visual search task, colored pictures of real-world objects were used in our actual experiments.

\section{SIMILARITY MAP}

A visual representation of how alike different items seem to people. The closer items are located to each other in the map, the more alike people think they are.
Which one did you see before?

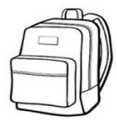

(a)

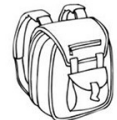

(b)

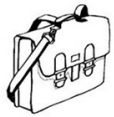

(c)

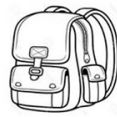

(d)
Figure 2

pictures that they tried to ignore earlier. For instance, without looking back, which backpack in Figure 2 appeared in Figure 1?

If you chose " $d$ " then you chose correctly! On average, people in our experiment chose the correct answer over $60 \%$ of the time (around 90 out of 150 attempts). This might not sound like a lot to you, but if people randomly guessed by closing their eyes and picking, they would have only been correct $25 \%$ of the time (about 38 out of 150 attempts). Remember, this is incidental memory: in their searches, people tried to ignore, not remember, these pictures.

\section{HOW ACCURATE IS INCIDENTAL MEMORY?}

Knowing that people incidentally remember over $60 \%$ of the objects does not tell us how well-they remembered them. To answer this question, we looked at the mistakes people made. If you look back at Figure 2, you probably notice that option "c" does not look at all like the correct answer. On the other hand, option "b" looks very similar to the correct backpack, and option "a" is somewhere in the middle. This is the sort of multiple-choice test people in our experiment took-they had to choose the correct object from others that were "very similar," "moderately similar," and "not similar" to the correct answer.

Although the concept of similarity is intuitive, we used similarity maps to scientifically measure how much pictures did (or did not) look alike [5]. Similarity maps can be created by asking people to arrange pictures according to how similar they think they are (Figure 3A). Similar pictures are put close to each other, and as pictures become more and more different, they are located further away from each other. When lots of people do this task, researchers can then get reliable similarity maps for many categories of objects.

Using similarity maps, we found that the "very similar" (but incorrect) choice was selected more often than the "moderately similar" and "not similar" choices (Figure 3B). This was not random guessing! If people guessed randomly, they would have been equally likely to pick each object. Instead, they selected the "very similar" object most often and 
Figure 3

(A) An example of a similarity map for pictures of backpacks. Pictures that are similar to each other are grouped close together. Pictures that are dissimilar are further apart. The red arrows highlight the "distance" between the backpacks in Figure 2, with shorter arrows reflecting greater similarity. (B) In our experiment, participants were much more likely to choose a mistaken backpack that was very similar to the actual backpack pictured. The red dotted line reflects an equal likelihood of randomly picking any of the three incorrect choices $(33.33 \%)$.

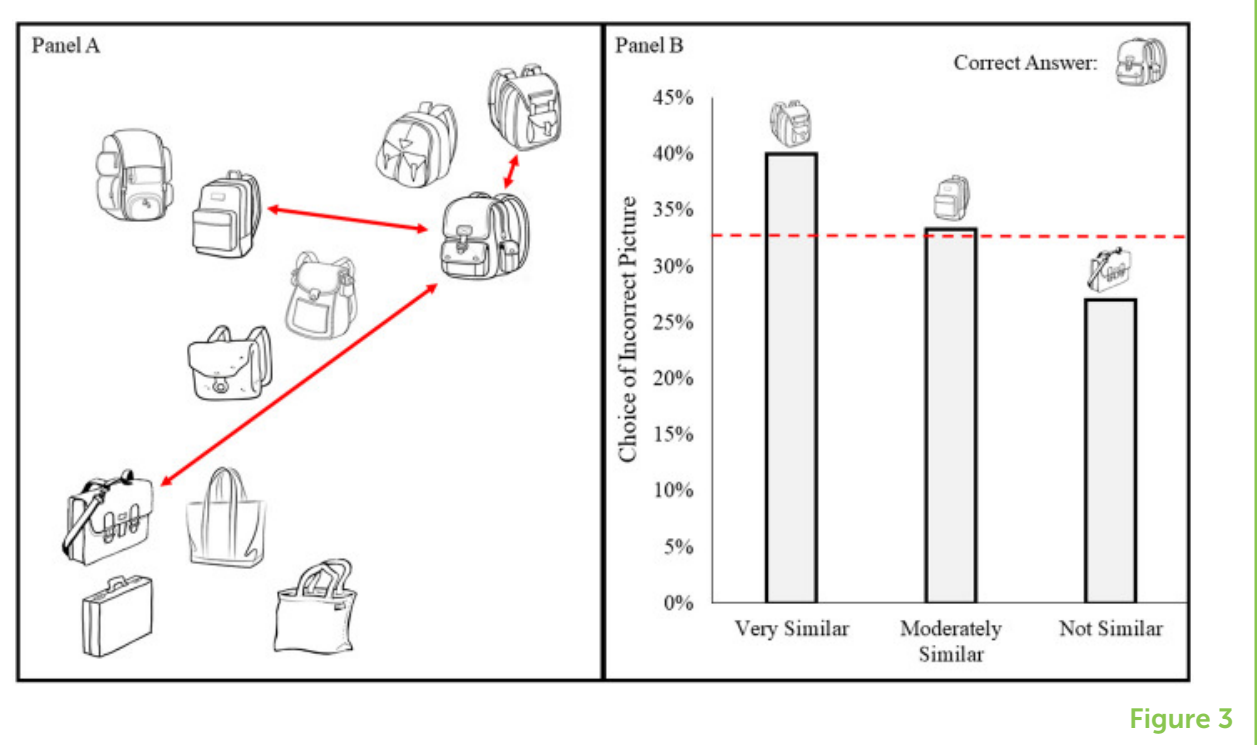

the "not similar" object least often. This is like bringing Jeff the wrong brown jacket instead of bringing him the wrong blue jacket. Both jackets are "wrong," but one is less wrong than the other. Importantly, this suggests that visual items are not entirely forgotten: some part of the memory persists, even if we answer incorrectly.

Although the search example shown in Figure 1 is pretty easy, we increased the difficulty in some aspects of our experiment. For example, sometimes people only searched for one thing (like a jacket). Other times, they searched for three things (like a jacket, a dog, and a rocket) at the same time, but only one of those things might appear, so people never knew what to expect. When the task became more challenging like this, people actually had better memory for the distracting pictures! We believe this occurs because people must pay close attention to the pictures when they are less sure of what they might (or might not) find.

\section{CONCLUSION}

Our experiment demonstrates that picture memories, including those formed incidentally, are quite detailed, even when we cannot perfectly remember what we saw. Perfect remembering is actually rather rare, especially if you do not pay attention and study hard! However, having less-than-perfect memories does not mean that we have totally forgotten. Instead, we can forget some aspects of a picture while remembering others, which shows that the memory is in your brain somewhere. Some researchers think that we store individual pieces or features in memory, and then we later "remember" by putting the whole picture back together. Indeed, when you try to remember a picture, the same regions of the brain's visual cortex become active as if you are actually seeing the picture! 
At a practical level, this research might help you in school. Even though you should always study to form intentional memories of your lessons, your incidental memory might help you in cases where you might have forgotten some information you intentionally learned. We form incidental memories all the time, and not just for visual material. So, if you are taking a test and you are not sure of the correct answer, go with your gut! Odds are that you have an incidental memory for the correct answer, so even if you choose incorrectly, your choice may be similar enough to the correct answer that your teacher may give you partial credit for it!

\section{ORIGINAL SOURCE ARTICLE}

Guevara Pinto, J. D., Papesh, M. H., and Hout, M. C. (2021). The detail is in the difficulty: challenging search facilitates rich incidental object encoding. Mem. Cogn. 48, 1214-1233. doi: 10.3758/s13421-02001051-3

\section{REFERENCES}

1. Standing, L. 1973. Learning 10,000 pictures. Q. J. Exp. Psychol. 25:207-22.

2. Hout, M. C., and Goldinger, S. D. 2012. Incidental learning speeds visual search by lowering response thresholds, not by improving efficiency: Evidence from eye movements. J. Exp. Psychol. Hum. Percept. Perform. 38:90-112. doi: $10.1037 / a 0023894$

3. Castelhano, M. S., and Henderson, J. M. 2005. Incidental visual memory for objects in scenes. Vis. Cogn. 12, 1017-40. doi: 10.1080/13506280444000634

4. Williams, C. C. 2010. Incidental and intentional visual memory: what memories are and are not affected by encoding task? Vis. Cogn. 18:1348-67. doi: 10.1080/ 13506285.2010 .486280

5. Hout, M. C., Goldinger, S. D., and Brady, K. J. 2014. MM-MDS: a multidimensional scaling database with similarity ratings for 240 object categories from the massive memory picture database. PLOS ONE. 9:e112644. doi: 10.1371/journal. pone.0112644

SUBMITTED: 28 July 2020; ACCEPTED: 01 September 2021;

PUBLISHED ONLINE: 30 September 2021.

EDITED BY: Guilherme Lucas, University of São Paulo, Brazil

CITATION: Guevara Pinto JD, Papesh MH and Hout MC (2021) Learning by Accident: Some Memory Mistakes Are Not Totally Wrong. Front. Young Minds 9:588337. doi: 10.3389/frym.2021.588337

DISCLAIMER: Any opinions, findings, and conclusions expressed in this material are those of the authors and do not necessarily reflect the views of the National Science Foundation. 

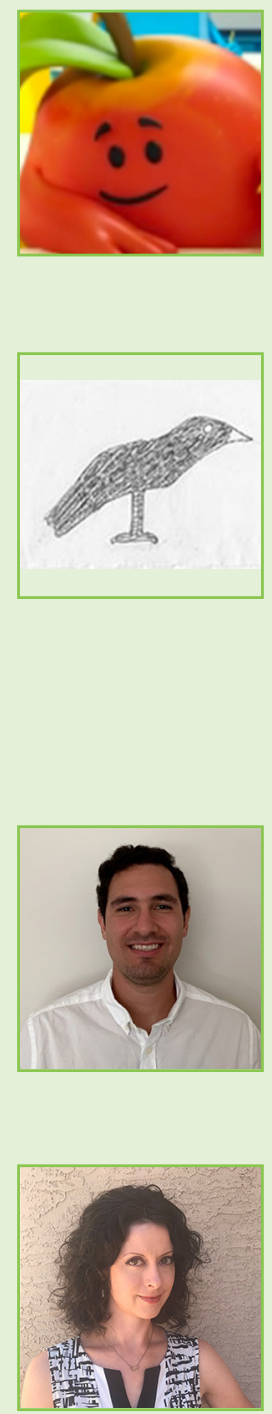

CONFLICT OF INTEREST: The authors declare that the research was conducted in the absence of any commercial or financial relationships that could be construed as a potential conflict of interest.

COPYRIGHT () 2021 Guevara Pinto, Papesh and Hout. This is an open-access article distributed under the terms of the Creative Commons Attribution License (CC BY). The use, distribution or reproduction in other forums is permitted, provided the original author(s) and the copyright owner(s) are credited and that the original publication in this journal is cited, in accordance with accepted academic practice. No use, distribution or reproduction is permitted which does not comply with these terms.

\section{YOUNG REVIEWERS}

\section{DALLIN, AGE: 12}

Hello my name is Dallin. I like hiking, biking, and any outdoor thing. I also like reading and playing video games, also my family loves traveling.

\section{WILDER, AGE: 12}

Wilder would like to write a book before 18 and travel to Madagascar and British Columbia. He loves to be active and have fun with his family and friends and also enjoys playing the trombone and ukelele. He likes playing board games and sports like soccer he also loves reading fantasy books. Wilder likes people who are tolerant of sarcasm and have a good sense of humor.

\section{AUTHORS}

\section{JUAN D. GUEVARA PINTO}

Juan D. Guevara Pinto is an Assistant Professor in the Department of Psychology at Rollins College. His research examines how our expectations impact the way we attend and remember the different things we encounter. In his limited free time he enjoys playing soccer, riding his bike, and exploring the city of Orlando with his wife and dog. *jguevarapinto@rollins.edu

\section{MEGAN H. PAPESH}

Megan H. Papesh started her career in Psychology at Louisiana State University and is currently an Assistant Professor at New Mexico State University. Her laboratory investigates the brain and behavior in many domains, including human memory, face perception, visual search, and attention. She has won several teaching and research awards, including the Rising Star award from the Association for Psychological Science. In her free time, she enjoys spoiling her dog and going for hikes or bike rides. 


\section{MICHAEL C. HOUT}

Michael C. Hout is an Associate Professor in the Department of Psychology at New Mexico State University, and a Program Director at the National Science Foundation. His research focuses primarily on visual cognition (including search, attention, eye movements, and memory) and the development of methods of collecting similarity data for use in multi-dimensional scaling. He has won several awards for research and teaching, including the Rising Star award from the Association for Psychological Science. In his limited free time, he enjoys walking his dog, running, hiking, and playing hockey. 